\title{
Hematospermia: footprint of severe uncontrolled hypertension
}

Keywords: hematospermia, oligozoospermia, azoospermia, asthenozoospermia, hematuria

\section{Introduction}

Hematospermia, also known as hemospermia, bloody sperm and sanguineous sperm, is a commonly isolated symptom characterized by the presence of glossy visible blood in semen and represents $1 \%$ of all andrological and urological symptoms. ${ }^{1}$ Historical evidences revealed that it had been reported by Hippocrates, Pares, Morgagni, Velpeau, Fournier and Guyon. ${ }^{2,3}$ It is usually painless but can be seen along with hematuria, frequency, dysuria and scrotal pain as well as infertility. ${ }^{4,5}$ It has been indicated that hematospermia can result in azoospermia, oligozoospermia and asthenozoospermia leading to male infertility. ${ }^{6,7}$ Moreover, it often leads to substantial adverse psychological consequences in the patient. ${ }^{8}$ It was found that $77.50 \%$ of men with hematospermia had experienced only one or two episodes prior to visiting urologists. ${ }^{5}$ The incidence of hematospermia has been reported as one in every 5,000 new patients presenting to urological out-patient clinics. Most men with hematospermia are likely to be less than 40 years old with symptoms ranging from a few weeks to a few months in duration. The likelihood of recurrent hematospermia is seen in the older age group. ${ }^{9}$

Most often the causes of hematospermia are idiopathic and the precise etiology of this disorder cannot be found in as many as 70 percent of patients. ${ }^{8,9}$ Based on etiological origins, hematospermia as a mono-symptomatic and/or poly-symptomatic disorder has congenital, inflammatory, infective, traumatic, obstructive, neoplastic, iatrogenic and systemic causes. ${ }^{8,10}$ Although hematospermia is usually a symptom of urological problems, severe uncontrolled hypertension as a systemic disorder may be the cause. ${ }^{11-13}$ In line with that, previous studies declared that hypertension can be detected in $7.30 \%$ of the patients with hemospermia. ${ }^{14}$ Based on this concept, since hemospermia treatment depends on the underlying pathological conditions, careful clinical assessments including endorectal magnetic resonance imaging and trans rectal ultrasound ${ }^{15-18}$ as well as full general examination including blood pressure readings should be carried out to trace the source of hematospermia and establish efficient therapeutic strategies.

\section{Acknowledgements}

None.

\section{Conflict of interest}

The author declares no conflict of interest.

\section{References}

1. Razek AA, Elhanbly S, Eldeak A. Transrectal ultrasound in patients with hematospermia. J Ultrasound. 2010;13(1):28-33.

2. Mulhall JP, Albertsen PC. Haemospermia: diagnosis and management. Urology. 1995;46(4):463-467.

3. Munkel witz R, Krasnokutsky S, Lie J, et al. Current perspectives on hematospermia: a review. J Androl. 1997;18(1):6-14.
Volume 3 Issue 2 - 2016

\author{
Ali Shalizar Jalali \\ Department of Basic Sciences, Urmia University, Iran
}

Correspondence: Ali Shalizar Jalali, Histology and Embryology Research Laboratories, Department of Basic Sciences, Faculty of Veterinary Medicine, Urmia University, Urmia, Iran, Fax 00984432771926, Tel 00984431942593,

Email ali_shalizar@yahoo.com, a.shalizar@urmia.ac.ir

Received: October 26, 2016 | Published: December 22, 2016

4. Weidner W, Jantos C, Schumacher F, et al. Recurrent haemospermia. Underlying urogenital anomalies and efficacy of imaging procedures. $\mathrm{Br}$ J Urol. 1991;67(3):317-323.

5. Jones DJ. Haemospermia: a prospective study. British Journal of Urology. 1991;67(1):88-90.

6. Mundy AJ, Ryder TA, Edmonds DK. Asthenozoospermia and the human sperm mid-piece. Hum Reprod. 1995;10(1):116-119.

7. Singh Iqbal. The sanguineous sperm (hemospermia)-current appraisal and review. Indian Journal of Surgery. 2005;67(6):302-307.

8. Kumar P, Kapoor S, Nargund V. Haematospermia-a systemic review. Ann R Coll Surg Engl. 2006;88(4):339-342.

9. Akhter W, Khan F, Chinegwundoh F. Should every patient with hematospermia be investigated? A critical review. Cent European J Urol. 2013;66(1):79-82.

10. Papp GK, Hoznek A, Hegedüs M, et al. Hematospermia. J Androl. 1994;15:31S-33S.

11. Hamburger S, Styczynski M, O’Hearne J, et al. Hemospermia and hypertension-two case reports. J Kans Med Soc. 1980;81(10):459-460.

12. Iversen PS. Hemospermia and hypertension. Ugeskr Laeger. 1987;149(9):596.

13. Bhaduri S, Riley VC. Haematospermia associated with malignant hypertension. Sex Transm Infect. 1999;75(3):200.

14. Kochakarn W, Leenanupunth C, Olarn KR, et al. Hemospermia: review of the management with 5 years follow-up. J Med Assoc Thai. 2001;84(11):1518-1521.

15. Cho IR, Lee MS, Rha KH, et al. Magnetic resonance imaging in hemospermia. J Urol. 1997;157(1):258-262.

16. Yagci C, Kupeli S, Tok C, et al. Efficacy of transrectal ultrasonography in the evaluation of hematospermia. Clin Imaging. 2004;28(4):286-290.

17. Jianquan Z. Diagnosis and therapeutics of the causative diseases for hemospermia on transrectal ultrasound. Ultrasound Med Biol. 2006;32:S249.

18. Prando A. Endorectal magnetic resonance imaging in persistent hemospermia. Int Braz J Urol. 2008;34(2):171-177. 